\title{
Prevalence of Otitis Media Among Patients Attending Otorhinolaryngology Clinic in Ramadi City/Iraq
}

\author{
Original \\ Article
}

\author{
Raid M. Al-Ani
}

Department of Surgery (Otolaryngology), College of Medicine, University of Anbar, Anbar, Iraq

\begin{abstract}
Objective: This study aimed to evaluate the prevalence of various types of otitis media.

Patients and Methods: A cross-sectional observational prospective study conducted in AL-Ramadi city/Iraq during the year 2018. Individuals who attending an Otorhinolaryngology outpatient clinic with the diagnosis of acute suppurative otitis media (ASOM), otitis media with effusion (OME) and chronic suppurative otitis media (CSOM) were analyzed. While any subject or their relatives who don't wish to participate in the study was excluded.

Results: The age of the patients ranged from 1 month to 76 years (mean age $=10.2$ years \pm 9.027 ). Five hundred fortyseven $(54.91 \%)$ were males and 449 (45.09\%) females (male to female ratio, 1.2:1). Out of 7292 cases attending Otorhinolaryngology outpatient clinic, a 996 (13.65\%) cases had otitis media. During February, the peak frequency of OM was seen 122 (23.64\%), while during April the least frequency $59(9.57 \%)$. OM was seen in around 50\% in the age group $>18$ years. While, only $225(22.59 \%)$ in age group $<5$ years. Four hundred and four $(40.56 \%)$ had OME, 331 (33.23\%) had CSOM, while 261 (26.21\%) had ASOM. The observed distribution of the OM was left OM (37.56\%, $\mathrm{n}=374)$, right $\mathrm{OM}(34.63 \%, \mathrm{n}=345)$ and bilateral $\mathrm{OM}(27.81 \%, \mathrm{n}=277)$.

Conclusions: Otitis media has a prevalence of $13.65 \%$ among patients attending the Otorhinolaryngology outpatient clinic. Lack of guidelines in Iraq for treating OM has a drawback in the management of this common disease.
\end{abstract}

Key Words: Acute suppurative otitis media, chronic suppurative otitis media, glue ear, otitis media, otitis media with effusion.

Received: $21^{\text {th }}$ July 2019, Accepted: $07^{\text {th }}$ September 2019

Corresponding Author: Raid M. Al-Ani, Department of Surgery (Otolaryngology), College of Medicine, University of Anbar, Anbar, Iraq, Tel.: 009647906145364, E-mail: raedalani2003@yahoo.com

ISSN: 2090-0740, March 2020 Vol. 21, No. 1.

\section{INTRODUCTION}

Ear infections including otitis media $(\mathrm{OM})$ and hearing loss are usually neglected problems in developing countries $^{[1]}$. Infants and children are most commonly affected by OM, however, adults are not exempted. The countries are paid too much money for the treatment of this disease, for example, in the USA, the medical cost per year for this disease 5 billion $\$^{[2]}$. OM can result in various morbidity and even mortality if it is not treated promptly and in time. There are two problems in most of developing countries, including Iraq, firstly, there are no guidelines for treating OM and upper respiratory tract infection, and secondly, the patient or their relative are buying directly from the pharmacies without an official mandatory prescription from a doctor ${ }^{[3]}$.

$\mathrm{OM}$ is a group of infectious and inflammatory disorders involving the middle ear cleft, with different subtypes varying in the mode of presentation, related complications, and the options of treatment. These are acute suppurative otitis media (ASOM), otitis media with effusion (OME) and CSOM (chronic suppurative otitis media). Both ASOM and OME are characterized by the presence of middle ear effusion (MEE) ${ }^{[4]}$. OME can be defined as the presence of mucus inside the middle ear and maybe inside the mastoid air cells. If the condition persists for 3 months or more, is called chronic $\mathrm{OME}^{[5]}$. Acute otitis media (AOM) is defined as acute onset inflammation of the middle ear and mastoid air cells, characterized by the presence of purulent fluid within the middle ear and associated with different symptoms and clinical signs ${ }^{[6]}$. ASOM is similar to AOM. It usually occurs behind an eardrum, but may develop in the presence of grommet or existing eardrum perforations. In the past, CSOM is defined as chronic inflammation of the middle ear cleft, characterized by intermittent or persistence aural discharge through an eardrum perforation and deafness ${ }^{[7]}$. CSOM definitions were heterogeneous and included ear discharge for $>2$ weeks by previous researchers $^{[8-10]}$, While other researchers considered the duration of the aural discharge $>6$ weeks for the completion of the definition of $\mathrm{CSOM}^{[11]}$. Nowadays, It is better to use the term chronic otitis media (COM) because it covers any chronic inflammatory process within the middle ear cleft whether the eardrum is perforated or not. In general, COM can be classified into COM with cholesteatoma or $\mathrm{COM}$ without cholesteatoma ${ }^{[7]}$.

In a review study by DeAntonio et al ${ }^{[3]}$, they found that the prevalence of OM in children less than 6 years old varies from $6.7 \%$ in China to $10 \%$ in Egypt. There is a lack of studies focusing on the prevalence of $\mathrm{OM}$ in our country. Herein we studied and registered the prevalence of OM among patients attending an Otolaryngology clinic in AL-Ramadi city/Iraq. 


\section{PATIENTS AND METHODS}

This a prospective study was carried out in the AL-Ramadi city/Iraq during the year 2018. The study was approved by the Surgical Department, College of Medicine, University of Anbar. Out of 7292 patients who attended the Otolaryngology clinic in AL-Ramadi city/ Iraq, 996 (13.65\%) were diagnosed as OM and enrolled in the study. Informed consent was taken from every subject or their parents. Patients or their relatives who don't wish to participate in the study were excluded from the study.

After a careful history with particular attention to the age, gender, chief complaint, duration, onset, side, recurrence and any previous treatment, complete ear, nose and throat (ENT) examination were carried out by one of the 8 otolaryngologists (including the author) in our hospital. For the evaluation of the state of the ears, they used auriscope or rigid telescope and if necessary microscopic examination with suction clearance was done, then the patients were sent for pure tone audiometry, tympanometry, bacteriological examination of ear swab and imaging study when indicated.

\section{The patients were classified into 3 groups}

1. ASOM: the diagnosis of ASOM was based on a clinical complaint of ear pain combined with a finding of middle-ear effusion, in addition to at least 1 other indicator of acute inflammation, namely, marked redness or distinct fullness or bulging of the tympanic membrane.

2. OME: the presence of middle-ear effusion was determined by decreased or absent mobilities of the tympanic membrane on pneumatic otoscopy, opacification of the tympanic membrane for reasons other than scarring, or visible bubbles or air-fluid level behind the tympanic membrane and the "B" curve on the tympanogram.

3. CSOM: diagnosed when there is a chronic middle ear discharge through a perforated tympanic membrane plus conductive hearing loss, of duration more than 6 weeks.

The age groups of patients with OM were divided into 3 groups: $<5$ years, $5-18$ year and $>18$ years. The frequency of OM per each month in regards the total number of patients attending the outpatient clinic was registered.

The data were analyzed using the statistical package for social sciences version 22 (SPSS 22). The data were presented as frequencies in tables.

\section{RESULTS}

Out of 7292 patients were seen during the study period,
$996(13.65 \%)$ cases with otitis media were analyzed (Table 1). Five hundred forty-seven $(54.91 \%)$ were males and $449(45.09 \%)$ females (male to female ratio, 1.2:1) (Table 2). The age range of the cases studied was 1 month-76 years (mean $=10.2$ years \pm 9.027 ).

Table 1: Frequency of OM in relation to the all patients per month

\begin{tabular}{ccc}
\hline Month & All patients N(\%) & Patients with OM N(\%) \\
\hline January & $388(100 \%)$ & $82(21.13 \%)$ \\
February & $516(100 \%)$ & $122(23.64 \%)$ \\
March & $668(100 \%)$ & $110(16.46 \%)$ \\
April & $616(100 \%)$ & $59(9.57 \%)$ \\
May & $660(100 \%)$ & $73(11.06 \%)$ \\
June & $520(100 \%)$ & $59(11.34 \%)$ \\
July & $750(100 \%)$ & $81(10.8 \%)$ \\
August & $760(100 \%)$ & $79(10.39 \%)$ \\
September & $485(100 \%)$ & $48(9.89 \%)$ \\
October & $580(100 \%)$ & $74(12.75 \%)$ \\
November & $723(100 \%)$ & $88(12.17 \%)$ \\
December & $626(100 \%)$ & $121(19.32 \%)$ \\
Total & $7292(100 \%)$ & $996(13.65 \%)$ \\
\hline
\end{tabular}

The peak frequency of OM was seen during February 122 (23.64\%), while the least frequency was seen during April 59 (9.57\%) Table 1. The peak age of incidence was found to be in the age group $>18$ years 491 (49.3\%), while the least age of occurrence was found to be in the age group less than 5 years $225(22.59 \%)$ (Table 2$)$.

Table 2: Age and sex of patients with $996 \mathrm{OM}$

\begin{tabular}{ccc}
\hline Age group & Male No.(\%) & Female No.(\%) \\
\hline$<5$ years & $134(53.2)$ & $91(46.8)$ \\
$5-18$ years & $167(77.95)$ & $113(22.05)$ \\
$>18$ years & $246(54.91)$ & $245(5.8)$ \\
Total & $547(54.91)$ & $449(45.09)$ \\
\hline
\end{tabular}

Four hundred four patients $(40.56 \%)$ had OME, 331 (33.23\%) had CSOM, while 261 (26.21\%) had ASOM. $72.19 \%(\mathrm{n}=719)$ of cases had unilateral OM, 52\% of these $(n=374)$ had left ear primarily affected, while $48 \%$ $(\mathrm{n}=345)$ had a right ear primarily affected. The remaining $27.81 \%(\mathrm{n}=277)$ of the cases studied had bilateral involvement, giving a total of 1273 ears. The observed distribution of the OME was left OME $(25 \%, \mathrm{n}=101)$, right OME $(28.2 \%, \mathrm{n}=114)$ and bilateral OME $(46.8 \%$, $\mathrm{n}=189$ ), while the CSOM is distributed into left CSOM $(44.12 \%, \mathrm{n}=146)$, bilateral CSOM $(22.05 \%, \mathrm{n}=73)$ and right CSOM $(33.83 \%, \mathrm{n}=112)$, and ASOM is distributed into right $\mathrm{AOM}(45.6 \%, \mathrm{n}=119)$, left $\mathrm{AOM}(48.6 \%, \mathrm{n}=$ $127)$, and bilateral $\mathrm{AOM}(5.8 \%, \mathrm{n}=15)$ (Table 3$)$. 
Table 3: Age and Sex distribution by Diagnosis of 996 patients with otitis media

\begin{tabular}{|c|c|c|c|c|c|c|}
\hline Diagnosis & Total No. $(100 \%)$ & $<5$ years No.(\%) & 5-18years No.(\%) & $>18$ years No. $(\%)$ & Males No. (\%) & Females No. $(\%)$ \\
\hline OME & 404 & $49(12.1 \%)$ & $125(30.9 \%)$ & $230(57 \%)$ & $241(60 \%)$ & $163(40 \%)$ \\
\hline Bilateral & 189 & $47(24.8 \%)$ & $100(52.9 \%)$ & $42(22.3 \%)$ & $116(61.3 \%)$ & $73(38.7 \%)$ \\
\hline Right ear & 114 & $1(0.8 \%)$ & $14(12.2 \%)$ & $99(87 \%)$ & $70(61.4 \%)$ & $44(38.6 \%)$ \\
\hline Left ear & 101 & $1(0.9 \%)$ & $11(11 \%)$ & $89(88.1 \%)$ & $55(54.5 \%)$ & $46(45.5 \%)$ \\
\hline CSOM & 331 & $36(10.9 \%)$ & $78(23.5 \%)$ & $217(65.6 \%)$ & $154(46.5 \%)$ & $177(53.5 \%)$ \\
\hline Bilateral & 73 & $15(20.5 \%)$ & $16(21.9 \%)$ & $42(47.6 \%)$ & $35(47.9 \%)$ & $38(52.1 \%)$ \\
\hline Right ear & 112 & $7(6.3 \%)$ & $31(27.6 \%)$ & $74(66.1 \%)$ & $51(45.5 \%)$ & $61(54.5 \%)$ \\
\hline Left ear & 146 & $14(9.5 \%)$ & $31(21.2 \%)$ & $101(69.3 \%)$ & $68(46.5 \%)$ & $78(53.5 \%)$ \\
\hline ASOM & 261 & $140(53.6 \%)$ & $77(29.5 \%)$ & $44(17.9 \%)$ & $152(58 \%)$ & $109(42 \%)$ \\
\hline Bilateral & 15 & $12(80 \%)$ & $3(20 \%)$ & $0(0 \%)$ & $7(47 \%)$ & $8(53 \%)$ \\
\hline Right ear & 119 & $60(50.5 \%)$ & $39(32.7 \%)$ & $20(16.8 \%)$ & $75(63 \%)$ & $44(37 \%)$ \\
\hline Left ear & 127 & $68(53.5 \%)$ & $35(27.5 \%)$ & $24(19 \%)$ & $70(59 \%)$ & $57(41 \%)$ \\
\hline
\end{tabular}

\section{DISCUSSION}

Otitis media is second in prevalence only to the common cold ${ }^{[12]}$. Previous studies investigating OM have reported prevalence ranging from $2.3 \%$ to $25.8 \%{ }^{[13-24]}$. The variability in these studies is likely secondary to differences in the type of study, patient population, and geographical location. The frequency of OM noted in the present study is in the middle of the range reported in the literature, but significantly lower than that noted in the study by Olusesi $\mathrm{AD}^{[16]}$. This discrepancy may be explained by a difference in the patient population. However, one shortcoming of the present study is that it is clinic-based, and so may not reflect true epidemiological pattern otitis media among the population studied.

Several risk factors might cause OM in all its different forms, like age, gender, family member number, economic status, daycare nursery, overcrowded housing, genetic factors, season, vaccination status, immunological status, nasal abnormalities, adenoids, and allergic rhinitis. This study showed 82 patients $(21.13 \%)$ had OM in January, 122 (23.64\%) in February and 121 (19.32\%) in December Table 1. So the present study supports the fact that OM is more common in winter owing to the high frequency of common cold, influenza and upper respiratory tract infections in the winter. In a recent study from Korea found that the incidence of $\mathrm{OM}$ in children with allergic rhinitis was double than those without allergic rhinitis ${ }^{[25]}$. A study by Muftah et $a l^{[26]}$ found that the overcrowded housing was the strongest negative impact for CSOM. One of the limitations of this study was not studied the effect of patient population allergen exposure, vaccination status, economic status and family member number on the prevalence of OM.

Acute inflammation of the middle-ear cleft is distinctly less common in adults than in children. This is due, it is thought, to regression of the adenoids, a reduction in the number of upper respiratory tract infections and possibly, as a result of the aforementioned conditions, more effective Eustachian tube function. But in this study, the frequency of OM nearly similar both in children and in adults, this in contrast with other studies ${ }^{[14,21]}$ whom they had been shown that the prevalence of OM much more common in children than in adults and that because, firstly, the study is not an epidemiological study, and secondly, most of the children were seeking advice of their middle ear inflammation to the General Practitioner and Pediatrician. So, we need in future an epidemiological study about $\mathrm{OM}$ to know the exact incidence and prevalence of OM in AL-Ramadi city.

Despite the difference in the population of patients in the present study and Olusesi AD study ${ }^{[16]}$, both studies had been revealed that $\mathrm{OME}$ is the commonest type of OM, followed by CSOM, while, ASOM is the least one. The Olusesi AD study showed only $9 \%$ of his patients were ASOM, which is much lower than the result of this study, this is assumed to the difference in patient population between both studies.

Many causes of OM (e.g. upper respiratory tract infections, adenoids, rhinosinusitis, and allergic rhinitis) are affecting both Eustachian tubes, so, it's possible theoretically that bilateral $\mathrm{OM}$ is more common than unilateral OM. But in a review of kinds of literature, we found only Olusesi AD study ${ }^{[16]}$ which was dealt with and put two possible causes of why unilateral $\mathrm{OM}$ is more common than bilateral OM (asymmetric nasal structure and unreported trauma). In the present study, about $3 / 4$ of cases were unilateral OM, but unfortunately, this study did not find any possible cause for the high frequency of unilateral $\mathrm{OM}$

ASOM has shown high rates of spontaneous resolution and minimal benefits of antibiotics; hence a policy of observation for 48-72 hours before initiating treatment is justified in many children ${ }^{[27]}$. As a result of the above, some cases of ASOM may be treated at home by some educated families as well as many patients with ASOM are treated by General Practitioners and Pediatricians. These 2 causes might explain the least frequency of ASOM in the present study in comparing to other types of OM. 
Owing to the high frequency of OM $(13.65 \%)$ in the present study, we recommend the ministry of health in Iraq to establish formal guidelines for the treatment of OM. Moreover, we also recommend the ministry of health in Iraq to create a strict low of prevention selling drugs by hand to the patients or their relatives without a prescription from treating doctors.

\section{CONCLUSION}

$\mathrm{OM}$ is a common disease with a frequency of $13.65 \%$ among patients attending an Otolaryngology clinic in this study. In order of frequency, OME has the highest frequency followed by CSOM and the lowest incidence is AOM. In Iraq, lack of guidelines for treating OM and haphazard buying antibiotic from the pharmacy from patients or their relatives have a strong negative impact on the management of such a common problem.

\section{CONFLICT OF INTEREST}

There are no conflict of interest.

\section{REFERENCES}

1. Adoga A, Nimkur T, Silas O. Chronic suppurative otitis media: Socio-economic implications in a tertiary hospital in Northern Nigeria. Pan Afr Med J. 2010;4(1).

2. Gates GA. Cost-effectiveness considerations in otitis media treatment. Otolaryngol Neck Surg. 1996;114(4):525-30.

3. DeAntonio R, Yarzabal J-P, Cruz JP, Schmidt JE, Kleijnen J. Epidemiology of otitis media in children from developing countries: A systematic review. Int J Pediatr Otorhinolaryngol. 2016;85:65-74.

4. Atkinson H, Wallis S, Coatesworth AP. Acute otitis media. Postgrad Med. 2015 May;127(4):386-90.

5. Robb PJ and Williamson I. Otitis media with effusion In Scott-Brown's Otorhinolaryngology Head and Neck Surgery. 8th edition. Taylor \& Francis Group, LLC; Vol 2 (2018): 115-36.

6. Rea PA and Ronan N. Acute otitis media In ScottBrown's Otorhinolaryngology Head and Neck Surgery. 8th edition. Taylor \& Francis Group, LLC; Vol 2 (2018): 137-54

7. Hellier WPL. Chronic otitis media In Scott-Brown's Otorhinolaryngology Head and Neck Surgery. 8th edition. Taylor \& Francis Group, LLC; Vol 2 (2018): $155-64$.

8. Wallis $\mathrm{S}$, Atkinson $\mathrm{H}$, Coatesworth AP. Chronic otitis media. Postgrad Med [Internet]. $2015 \mathrm{Jul}$ 4;127(4):391-5. Available from: https://doi.org/10.10 $80 / 00325481.2015 .1027133$
9. Couzos S, Lea T, Culbong M, Mueller R, Murray R. Effectiveness of ototopical antibiotics for chronic suppurative otitis media in Aboriginal children: a community based, multicentre, double blind randomised controlled trial. Med J Aust. 2003;179(4):185-90.

10. Jensen RG, Johansen HK, Bjarnsholt T, EickhardtSørensen SR, Homøe P. Recurrent otorrhea in chronic suppurative otitis media: is biofilm the missing link? Eur Arch Oto-Rhino-Laryngology. 2017;274(7): 2741-7.

11. Stephen ATN, Leach AJ, Morris PS. Impact of swimming on chronic suppurative otitis media in Aboriginal children: a randomised controlled trial Med J Aust. 2013;199(1):51-5.

12. Worrall G. Acute earache. Canadian Family Physician. 2011 Sep 1;57(9):1019-21.

13. Halama AR, Voogt GR, Musgrave GM. Prevalence of otitis media in children in a black rural community in Venda (South Africa). Int J Pediatr Otorhinolaryngol. 1986;11(1):73-7.

14. Halama AR, Voogt GR, Musgrave GM. Prevalence of otitis media in a Venda village. South African Med journal= Suid-Afrikaanse Tydskr vir Geneeskd. 1987;71(9):577-9.

15. Amusa YB, Ijadunola IKT, Onayade OO. Epidemiology of otitis media in a local tropical African population. West Afr J Med. 2005;24(3):227-30.

16. Olusesi AD. Otitis media as a cause of significant hearing loss among Nigerians. Int $\mathrm{J}$ Pediatr Otorhinolaryngol. 2008;72(6):787-92.

17. Mandel EM, Doyle WJ, Winther B, Alper CM. The incidence, prevalence and burden of $\mathrm{OM}$ in unselected children aged 1-8 years followed by weekly otoscopy through the "common cold" season. Int J Pediatr Otorhinolaryngol. 2008;72(4):491-9.

18. Homøe P, Christensen RB, Bretlau P. Prevalence of otitis media in a survey of 591 unselected Greenlandic children. Int J Pediatr Otorhinolaryngol. 1996;36(3):215-30.

19. Garcés-Sánchez M, Diez-Domingo J, de Labiada Alvarez T, Planelles V, Graullera M, Baldo JM, et al. Epidemiology and burden of acute otitis media in Valencia (Spain). In: Anales de pediatria (Barcelona, Spain: 2003). 2004. p. 125-32.

20. Kim CS, Jung HW, Yoo KY. Prevalence and risk factors of chronic otitis media in Korea: results of a nationwide survey. Acta Otolaryngol. 1993;113(3):369-75. 
21. Miller SA, Omene JA, Bluestone CD, Torkelson DW. A point prevalence of otitis media in a Nigerian village. Int J Pediatr Otorhinolaryngol. 1983;5:19-29.

22. Castagno LA, Lavinsky L. Otitis media in children: seasonal changes and socioeconomic level. Int $\mathrm{J}$ Pediatr Otorhinolaryngol. 2002;62(2):129-34.

23. Marchisio P, Principi N, Passali D, Salpietro DC, Boschi G, Chetri G, et al. Epidemiology and treatment of otitis media with effusion in children in the first year of primary school. Acta Otolaryngol. 1998;118(4):557-62.

24. Maharjan M, Bhandari S, Singh I, Mishra SC. Prevalence of otitis media in school going children in Eastern Nepal. Kathmandu Univ Med J (KUMJ). 2006;4(4):479-82.

25. Byeon $\mathrm{H}$. The association between allergic rhinitis and otitis media: A national representative sample of in South Korean children. Sci Rep. 2019;9(1):1610.

26. Salem Muftah IM, Faragher B, Brabin B. Prevalence of chronic suppurative otitis media (CSOM) and associated hearing impairment among school-aged children in Yemen. Oman Med J. 2015;30(5):358.

27. Baquero-Artigao F. Acute otitis media in the era of pneumococcal vaccination. Enferm Infecc Microbiol Clin. 2008;26(8):505-9. 